\title{
The Influence of Heating Time and Temperature on the Properties of CIGSSe Solar Cells
}

\author{
Marco Giacomo Flammini, ${ }^{1,2}$ Nicola Debernardi, ${ }^{1,2}$ Maxime Le Ster, ${ }^{2,3}$ Brendan Dunne, ${ }^{4}$ \\ Johan Bosman, ${ }^{2,3}$ and Mirjam Theelen ${ }^{1,2}$ \\ ${ }^{1}$ TNO, Thin Film Technology, High Tech Campus 21, 5656 AE Eindhoven, Netherlands \\ ${ }^{2}$ Solliance, High Tech Campus 21, 5656 AE Eindhoven, Netherlands \\ ${ }^{3}$ ECN, Solar Energy, Thin Film PV Technologies, High Tech Campus 21, 5656 AE Eindhoven, Netherlands \\ ${ }^{4}$ NEXCIS, 190 avenue Célestin Coq, 13790 Rousset Cedex, France
}

Correspondence should be addressed to Marco Giacomo Flammini; marco.flammini@hotmail.it

Received 15 April 2016; Revised 16 June 2016; Accepted 12 July 2016

Academic Editor: Prakash Basnyat

Copyright (c) 2016 Marco Giacomo Flammini et al. This is an open access article distributed under the Creative Commons Attribution License, which permits unrestricted use, distribution, and reproduction in any medium, provided the original work is properly cited.

\begin{abstract}
Nonencapsulated CIGSSe solar cells, with a silver grid, were exposed to different temperatures for various periods in order to measure the effect of the heat exposure in CIGSSe modules. The heat treatment time and temperature were varied during the experiments, which were executed at atmospheric conditions. In all the cases, after reaching a temperature of about $300^{\circ} \mathrm{C}$, the IV measurement showed a reduction of $2-3 \%$ in terms of $V_{\mathrm{OC}}$ and $J_{\mathrm{SC}}$. This is confirmed, respectively, by Raman and EQE measurements as well. The efficiency drop was $-7 \%,-29 \%$, and $-48 \%$, respectively, for 30 seconds, 300 seconds, and 600 seconds of exposure time. With temperatures larger than $225^{\circ} \mathrm{C}$, the series resistance starts to increase exponentially and a secondary barrier becomes visible in the $I V$ curve. This barrier prevents the extraction of electrons and consequently reducing the solar cells efficiency. Lock-in thermography demonstrated the formation of shunts on the mechanical scribes only for 300 and 600 seconds exposure times. The shunt resistance reduction is in the range of 5\% for all time periods.
\end{abstract}

\section{Introduction}

In the recent years, CIGS technology has shown notable progress in terms of performance and reliability. The research center ZSW (Zentrum für Sonnenenergie- und Wasserstoff) has achieved the world record efficiency of $21.7 \pm 0.7 \%$ on a CIGS sample of $0.5 \mathrm{~cm}^{2}$ deposited on glass substrate [1]. This development confirms the remarkable technological potential of thin film technology, which could lead to a further cost reduction in the manufacturing process of solar cells. Many researchers are focusing their attention on damp degradation mechanisms involved in $\mathrm{Cu}(\mathrm{In}, \mathrm{Ga})(\mathrm{S}, \mathrm{Se})_{2}$ in order to increase the lifetime and, consequently, to scale up the penetration into the market. On the other hand, less studies focus on heat treatment of the whole solar cells, which could give further information to what extend CIGS is able to withstand critical environment conditions. Ramanathan et al. [2] investigated the effect of high temperatures, and they found that CIGS samples did not show any changes in external quantum efficiency (EQE) when heated up to $360^{\circ} \mathrm{C}$ for 30 minutes. Secondary Ion Mass Spectrometry (SIMS) results indicated that the diffusion of Cadmium into the CIGS layer occurred after heating at $400^{\circ} \mathrm{C}$ and concluded that the deterioration in terms of cell performance was attributable to the excess of $\mathrm{Cd}$ in the absorber layer and that CIGS devices are stable below $350^{\circ} \mathrm{C}$. Kijima and Nakada [3] have conducted heat treatments on CIGS in air environments and have revealed significant changes already at a temperature of $250^{\circ} \mathrm{C}$, in both the optical and electrical properties. They observed a reduction of the buffer layer thickness which led to an improved EQE response in the short wavelength spectrum. The increase in bandgap was explained by migration of sulfur, which was confirmed by SIMS measurements. Figure 1 collects literature data of nonencapsulated CIGS solar cells 


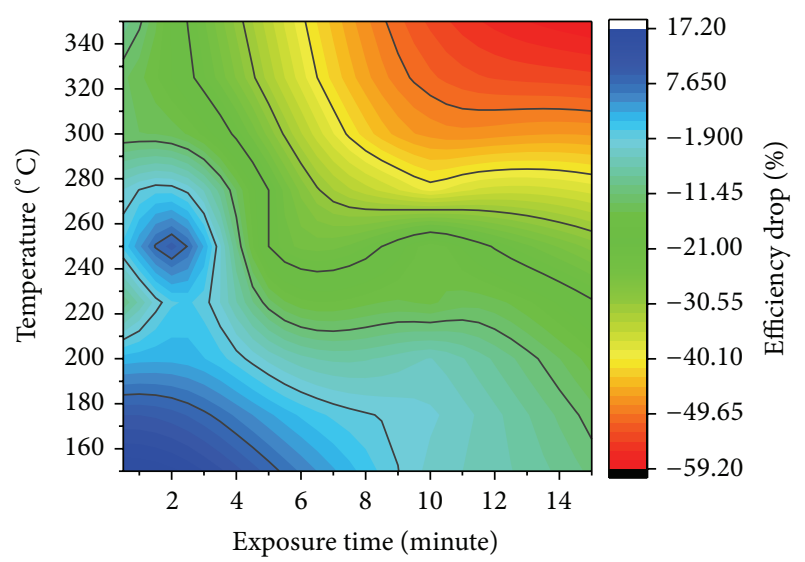

FIgURE 1: Effects on the efficiency of CIGS solar cells for different heat treatment conditions, as a function of time and temperature [27].

(initial efficiency: 7-15\%) exposed to noncumulative heat treatment, at room condition. The solar cells were exposed to different temperature conditions in atmospheric air.

It was observed that both exposure time and temperature have a large influence on the efficiency changes in these solar cells. It can be observed that for low temperatures and/or exposure times, the CIGS solar cells performance were improved by maximum $15 \%$. The critical temperature for CIGSSe solar cells were observed to be around $250^{\circ} \mathrm{C}$ for a heat treatment of at least 300 seconds. Moreover, exposure to elevated temperature can also be also important for tandem cells, in which CIGS is used as a bottom cell, as well as for the deposition of module packaging, like the encapsulation layer. In general, this reference gives an excellent overview regarding CIGS in inert ambient but only a few experiments have been conducted in atmosphere air environment. Therefore, the aim of this study is to investigate the effects of high temperature exposure on $\mathrm{Cu}(\mathrm{In}, \mathrm{Ga})(\mathrm{S}, \mathrm{Se})_{2}$, in the range of $150-300^{\circ} \mathrm{C}$ and for a period of $30 \mathrm{sec}-$ onds to 600 seconds, in order to understand the possible next processing temperature for TCO deposition, back-end interconnection, and encapsulation. Back-end processes that involve laser scribing are very likely to increase the local sample temperature at the positions where the laser beam hits the solar sample. Based on Finite Element Modeling we estimate that these temperature increments can go up to a few hundred degrees Celsius in the CIGS material in the direct vicinity of the scribe in case of insufficient ablation. In addition, this research could give valuable information regarding the ideal temperature for isolating and $\mathrm{Ag}$ sintering used for solar cells interconnections. This research can help to understand the feasibility of applying CIGS as a bottom cell in a tandem structure; indeed it will give an indication of the maximum temperature at which different layers can be deposited on top of CIGS. The aim of these experiments is to understand the influence of temperature for a certain amount of time on $\mathrm{Cu}(\mathrm{In}, \mathrm{Ga})(\mathrm{S}, \mathrm{Se})_{2}$ solar cells.
TABLE 1: Temperatures and time at which cells are exposed.

\begin{tabular}{lccc}
\hline \multicolumn{2}{c}{ Samples Number of cells } & Temperature $\left({ }^{\circ} \mathrm{C}\right)$ & $\begin{array}{c}\text { Time } \\
(\text { seconds })\end{array}$ \\
\hline A & 3 & - & - \\
B & 3 & $150,200,225,250,275,300$ & 30 \\
C & 3 & $150,200,225,250,275,300$ & 300 \\
D & 6 & $150,200,225,250,275,300$ & 600 \\
\hline
\end{tabular}

\section{Materials and Methods}

The CIGSSe solar cells structure is composed by molybdenum (Mo) back contact/two-stage CIGSSe absorber layer/Cadmium sulfide (CdS) as buffer layer/intrinsic zinc oxide (i- $\mathrm{ZnO})$ /aluminum doped zinc oxide ( $\mathrm{ZnO}: \mathrm{Al})$ as transparent conductive layer and a silver grid is screenprinted on top of the stack. The solar cells all have a surface area of $1 \mathrm{~cm}^{2}$ and are cut from one $10 \mathrm{~cm} \times 10 \mathrm{~cm}$ slide. This slide was obtained from the large scale production facilities of NEXCIS in France. Therefore, all samples are expected to be very similar. Silver ink has been applied on top of the Mo back contact in order to avoid Mo oxidation during heat treatment. Table 1 lists the samples used in the experiment and the exposure conditions applied. Sample A was used as a reference sample; meanwhile samples $B, C$, and $D$ have been, respectively, exposed for 30, 300, and 600 seconds, to all the temperatures mentioned in Table 1.

The samples B, C, and D were analyzed before being subjected to any heat treatment. Once the characterization was done, the solar cells were exposed to $150^{\circ} \mathrm{C}$ for different time periods. After the heat treatment the solar cells were analyzed again and the results compared. Once Step 2 was completed the solar cells were heated again at a higher temperature $\left(200^{\circ} \mathrm{C}\right)$ and the same characterization techniques were used again iteratively. Figure 2 indicates the process cycle for each temperature. The oven was heated to the required temperature.

Step 1 (warm-up of the oven). For each experiment the heating phase took about 20 minutes in order to stabilize the oven temperature. The relative humidity percentage was estimated to be below $10 \%$. Cells were then exposed to this temperature for the stated time. After analysis, the same samples were heated to the next temperature. This means that when we speak about the sample at $300^{\circ} \mathrm{C}$, it has already been cumulatively heated at $150^{\circ} \mathrm{C}, 200^{\circ} \mathrm{C}, 225^{\circ} \mathrm{C}, 250^{\circ} \mathrm{C}, 275^{\circ} \mathrm{C}$, and $300^{\circ} \mathrm{C}$ for 30 seconds each time in the case of group $\mathrm{B}$.

Step 2 (measurements). In this phase the samples B, C, and $\mathrm{D}$ were analyzed with current-voltage measurements (OAI TriSol solar Simulator). Series and shunt resistance, shown in Table 2, were obtained from the slope determination of the light current-voltage curves. Moreover, samples were analyzed by spectral response, LIT (ImageIR camera and Sunfilm IR lens from Infratec), optical microscopy, SIMS (Cameca IMS 7f), and SEM (Jeol/JSM-6010LA IntouchScope) images of back contact, grid, and samples surfaces. 
TABLE 2: Values of $V_{\mathrm{OC}}, J_{\mathrm{SC}}, F F, \eta, R_{\mathrm{S}}$, and $R_{\mathrm{SH}}$ at $25^{\circ} \mathrm{C}, 225^{\circ} \mathrm{C}$, and $300^{\circ} \mathrm{C}$.

\begin{tabular}{|c|c|c|c|c|c|c|c|c|c|c|}
\hline & \multicolumn{4}{|c|}{$25^{\circ} \mathrm{C}$} & \multicolumn{3}{|c|}{$225^{\circ} \mathrm{C}$} & \multicolumn{3}{|c|}{$300^{\circ} \mathrm{C}$} \\
\hline & A & B & $\mathrm{C}$ & $\mathrm{D}$ & $\mathrm{B}$ & C & $\mathrm{D}$ & $\mathrm{B}$ & C & $\mathrm{D}$ \\
\hline$V_{\mathrm{OC}}(\mathrm{mV})$ & $603 \pm 3$ & $603 \pm 4$ & $602 \pm 2$ & $601 \pm 2$ & $600 \pm 4$ & $587 \pm 2$ & $591 \pm 2$ & $598 \pm 4$ & $592 \pm 1$ & $585 \pm 2$ \\
\hline$J_{\mathrm{SC}}\left(\mathrm{mA} / \mathrm{cm}^{2}\right)$ & $36.1 \pm 0.2$ & $35.7 \pm 0.1$ & $36.3 \pm 0.2$ & $35.9 \pm 0.2$ & $36.4 \pm 0.1$ & $36.5 \pm 0.1$ & $36.1 \pm 0.3$ & $35.9 \pm 0.1$ & $36.2 \pm 0.2$ & $34.7 \pm 0.9$ \\
\hline$F F(\%)$ & $66 \pm 1$ & $68.1 \pm 1$ & $68.1 \pm 1$ & $66 \pm 1$ & $65 \pm 1$ & $65 \pm 2$ & $59 \pm 1$ & $64 \pm 1$ & $50 \pm 1$ & $37 \pm 1$ \\
\hline Efficiency (\%) & $14.3 \pm 0.1$ & $14.6 \pm 0.2$ & $14.9 \pm 0.3$ & $14.3 \pm 0.3$ & $14.2 \pm 0.1$ & $14.0 \pm 0.4$ & $12.8 \pm 0.1$ & $13.6 \pm 0.2$ & $10.6 \pm 0.2$ & $7.5 \pm 0.1$ \\
\hline$R_{S}\left(\Omega \mathrm{cm}^{2}\right)$ & $3.1 \pm 0.1$ & $2.8 \pm 0.1$ & $2.7 \pm 0.2$ & $3.1 \pm 0.2$ & $3.2 \pm 0.1$ & $2.9 \pm 0.3$ & $4.3 \pm 0.2$ & $3.6 \pm 0.1$ & $9.8 \pm 0.8$ & $27.1 \pm 1.0$ \\
\hline$R_{\mathrm{SH}}\left(\Omega \mathrm{cm}^{2}\right)$ & $1334 \pm 82$ & $1203 \pm 192$ & $1211 \pm 30$ & $1115 \pm 293$ & $1078 \pm 95$ & $1067 \pm 28$ & $1114 \pm 139$ & $1143 \pm 71$ & $1132 \pm 43$ & $1003 \pm 91$ \\
\hline
\end{tabular}

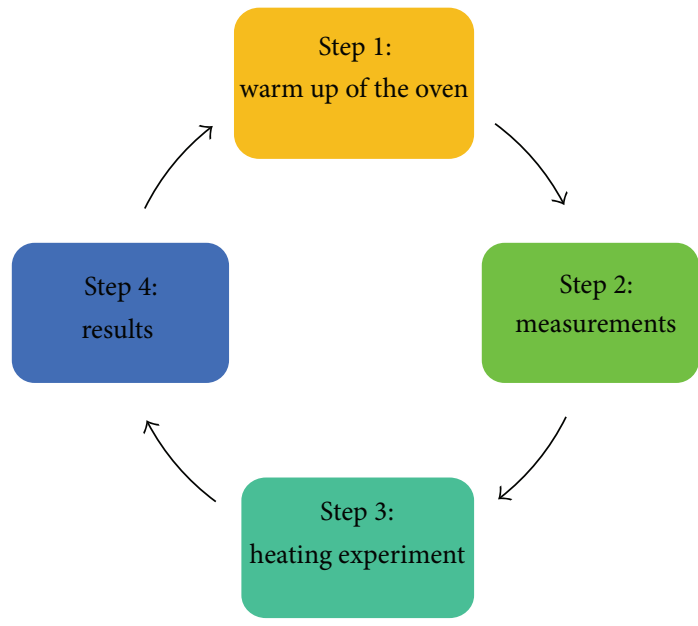

Figure 2: Cyclic steps for the heating experiments.

All these experiments gave an overview in terms of electrical, compositional, and visual aspects of the samples before they are exposed to heat treatment. Once this phase has been completed the cells are inserted in the oven and phase 3 begins.

Step 3 (heating experiment). The heating phase lasted, respectively, for 30 seconds, 300 seconds, and 600 seconds for the sample of groups B, C, and D. The temperature of the oven was monitored with a thermocouple located near the samples holder with an uncertainty of $5^{\circ} \mathrm{C}$. The samples were not preheated but directly inserted at the set temperature, at $1 \mathrm{bar}$, and in air atmosphere.

Step 4 (results). Once the heat treatment has been completed (for 30 seconds, 300 seconds, or 600 seconds), the samples were measured again with the same techniques of Step 1 and the results analyzed. The heat, due to this thermal mechanism, was accumulated after each cycle in the solar cell, so the same cells are exposed to the next temperature, and so on. Once the results are analyzed Step 1 starts again and the oven is warmed up till the next temperature.

\section{Experimental Results}

3.1. Electrical Changes. Before the heat treatment all the solar cells gave similar values of efficiency, $\mathrm{FF}, V_{\mathrm{OC}}, J_{\mathrm{SC}}$, and series

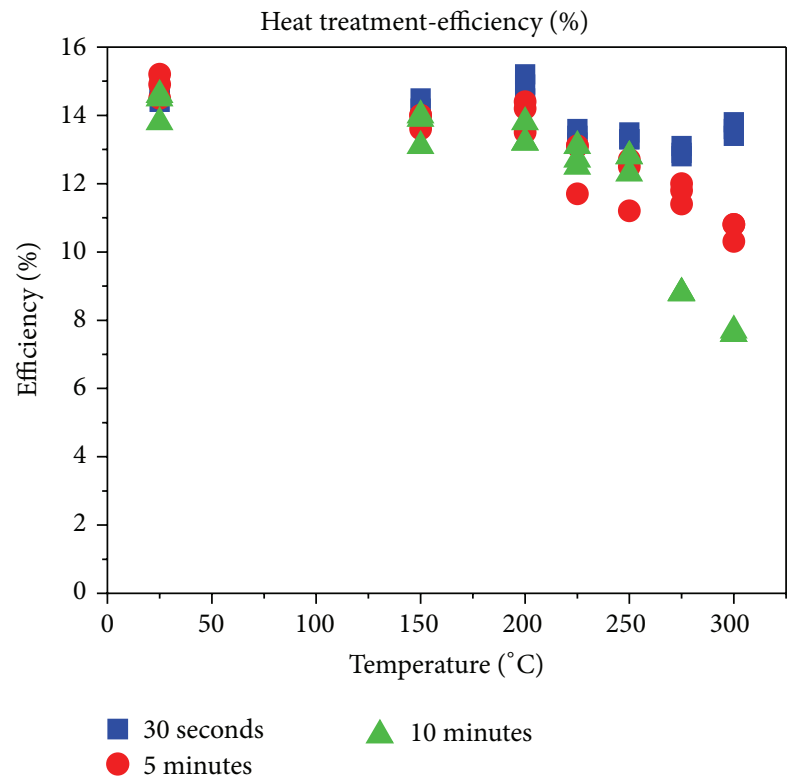

FIGURE 3: Efficiency evolution for different heat treatment condition. The 30 seconds (in blue), the 300 seconds (in red), and the 600 seconds (in green).

and shunt resistances, listed in Table 2. Below the critical temperature of $225^{\circ} \mathrm{C}$ barely any changes could be observed even for exposure of 600 seconds. The $I V$ measurements results, shown in Figure 3, point out that the efficiency reduction, after the exposure to $300^{\circ} \mathrm{C}$ for 30 seconds was limited to 2 $3 \%$; meanwhile in the cases of 300 seconds and 600 seconds it dropped by $30 \%$ and $50 \%$, respectively. Figure 4 shows the current-voltage curves for samples exposed to $300^{\circ} \mathrm{C}$ for 30 , 300 , and 600 seconds.

The $I V$ curves of the solar cells exposed to $300^{\circ} \mathrm{C}$ for 30 seconds (blue), 300 seconds (red), and 600 seconds (green) are plotted in Figure 4. The comparison of the $I V$ curve slope between the initial $I V$ slope and the final slope indicates the formation of a barrier for the cells exposed at 300 and 600 seconds. The barrier partly prevents the electrons' extraction.

The CIGSSe solar cells exposed for 30 seconds did not show any barrier formation in the $I V$ curve. The barrier formation, observable in Figure 4, firstly occurred at $225^{\circ} \mathrm{C}$, for samples heated for 300 and 600 seconds, and become more and more evident by increasing the exposure temperature. The $J_{\mathrm{SC}}$ and $V_{\mathrm{OC}}$ before and after the heat treatment were 


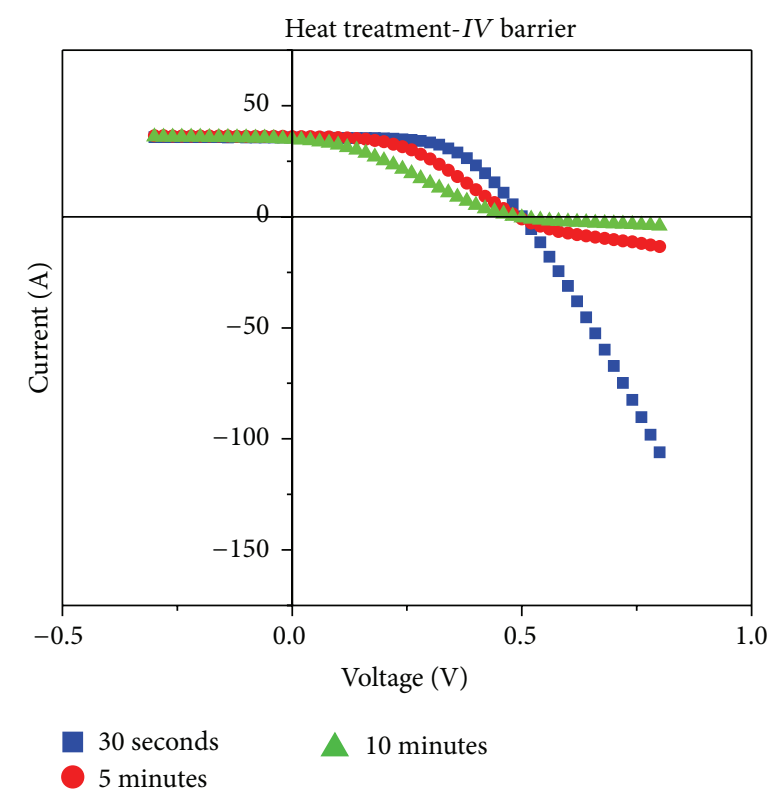

FIGURE 4: $I V$ curve barrier formation for heat treatment for 30 (in blue), 300 (in red), and 600 (in green) seconds after being exposed to $300^{\circ} \mathrm{C}$.

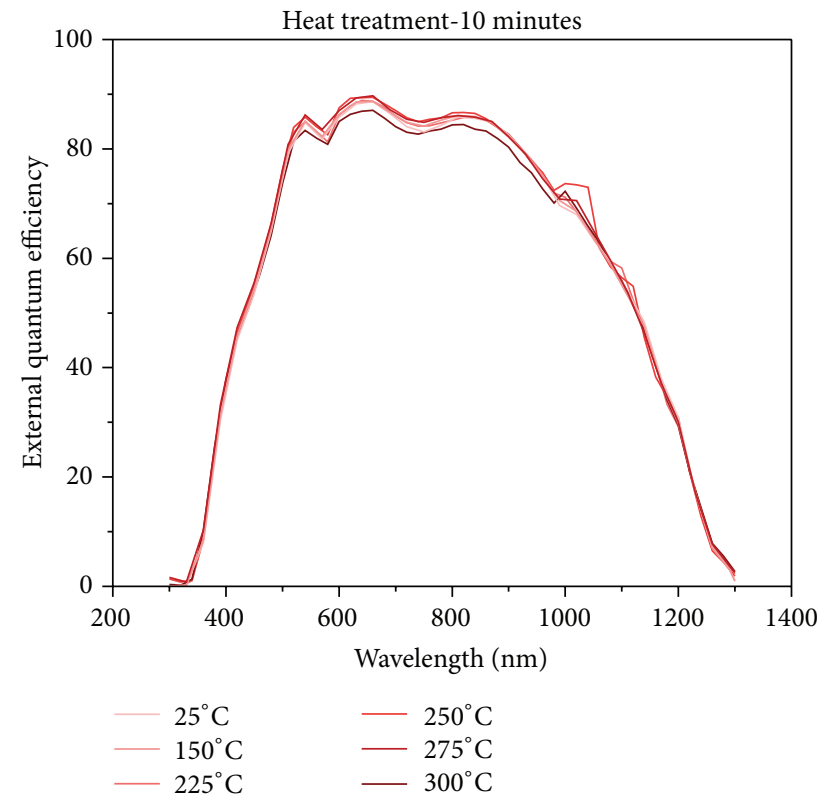

FIGURE 5: EQE of samples D heated for 600 seconds. The darker the color the more the heat treatment.

similar, which means that the electrons are still generated but not optimally extracted; this indicates the formation of a secondary barrier in the solar cell.

The EQE measurement, shown in Figure 5, indicated that, in the case of 600-second exposure time, the solar cells exposed to $300^{\circ} \mathrm{C}$ showed a global reduction in $J_{\mathrm{SC}}$ by maximum 2-3\%. These results confirmed the $I V$ measurements and are consistent with literature results, where a high EQE drop has been identified for temperature above $350^{\circ} \mathrm{C}[2,6,7]$.

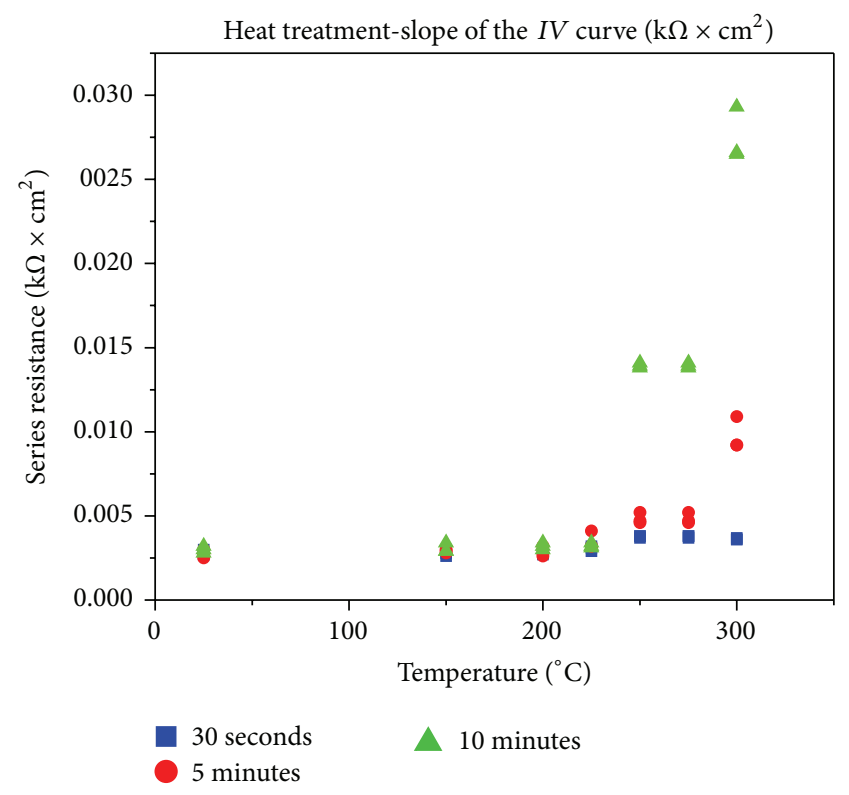

FIgURE 6: The slope of the $I V$ curve is a method to estimate the series resistance increase and consequently the barrier formation. In squares exposure of 30 seconds, in circles 300 seconds, and in triangles 600 seconds.

The EQE showed changes in the heated samples mainly in the region of 500-1000 nm wavelength. These changes could be caused by modification in the transparency of TCO or due to improvement in carrier collection. Figure 6 illustrates the slope of the $I V$ curve which represents the series resistance and/or the barrier evolution. The slope drastically increases after $225^{\circ} \mathrm{C}$ due to the barrier formation that bends the $I V$ curve and influences the series resistance calculation. The $V_{\mathrm{OC}}$ reduction was limited to a maximum value of $4 \%$ in all cases. Concerning the shunt resistance, the reduction was in the range of $5 \%$ in all the three time periods; meanwhile the increase in series resistance was negligible for the 30second exposure. In order to observe the evolution of the barrier, Figure 6 shows the slope of the $I V$ curve after the $V_{\mathrm{OC}}$ point. The value of the $I V$ curve slope is a simple method to estimate the effect of the series resistance on the performance of the solar cells. The barrier formation bends the $I V$ curve and heavily modifies the slope of the $I V$ curve and consequently the series resistance values. The main cause of the efficiency reduction is the barrier formation; indeed, it reduces the extraction of electrons. In case of 300 - and 600-second exposure time, the series resistance increase followed an exponential trend, with the increase in the exposure temperature, which was the main cause for high drops in terms of fill factor (50\%). In general, the results indicated that up to a temperature of $225^{\circ} \mathrm{C}$ the CIGS solar cells performance was not affected by the heat treatment.

Figure 7 illustrates the effect of applying different filters between the light source and the solar cells when performing $I V$ measurements in order to learn more about the cause of the barrier. The $J_{\mathrm{SC}}$ was corrected in order to properly compare the results. In the case of the blue filter, it is evident 


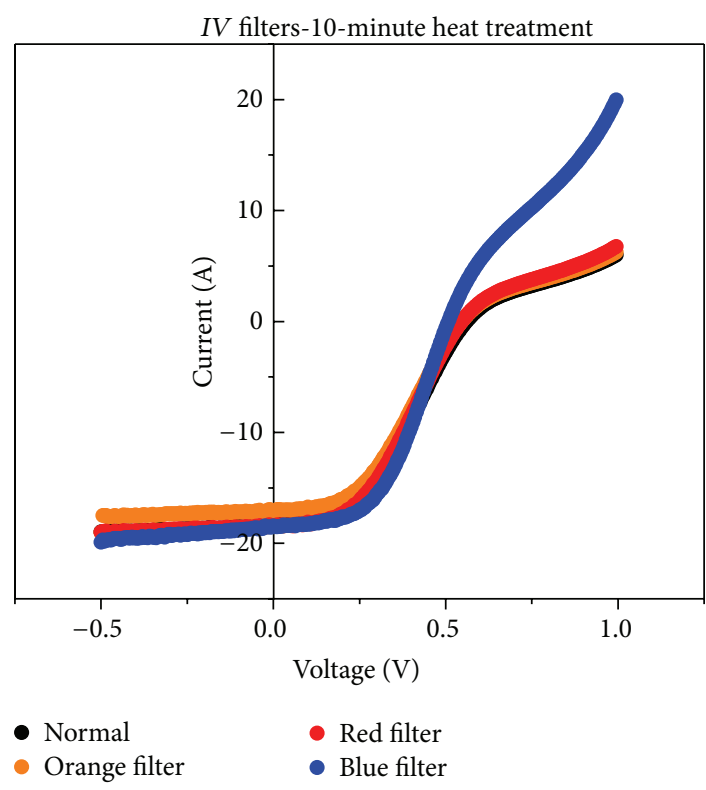

FIGURE 7: IV curve measurements under filters with a different color of the solar cells heated till $300^{\circ} \mathrm{C}$ for 600 seconds.

that the barrier is reduced and current is better extracted. The $I V$ curve produced by the use of the blue filter also indicates that the shape is not completely normal, but is closer to the expected behavior. A blue filter let only blue light pass through, meaning that $\mathrm{CdS}$ is excited and a normal behavior of the CIGSSe is observed. This could indicate that the barrier issue is more related to the front contact region rather than the back contact or CIGSSe absorber layer. In order to localize the observed shunting, lock-in thermography was used. The measurements are shown in Figure 8 and indicated the formation of shunts on the P3 mechanically scribes surrounding the $1 \mathrm{~cm}^{2}$ cells (white dashed lines). P3 lines were scribed mechanically when creating the interconnected cells. Those lines are visible in Figure 8, where we can notice shunt formation in vicinity of the scribes due to heat treatment. The shunts increase with the increasing in the exposure time. The blue line in Figure 8 represents the Ag grid of the solar cells. The figure shows the sample B ((a) exposed for 30 seconds), sample C ((b) exposed for 300 seconds), and sample D ((c) exposed for 600 seconds) after being exposed at a temperature of $300^{\circ} \mathrm{C}$. The increase in white color in the sample exposed for 600 seconds at $300^{\circ} \mathrm{C}$ indicate the degradation of the $\mathrm{P} 3$ line and consequently the increase in shunt resistance.

3.2. Compositional Changes. The compositional changes of the samples were studied by SEM-EDX and SIMS. The reference sample A was compared, by cross-sectional SEMEDX, with sample D. The latter is chosen because it showed the strongest barrier behavior since it was exposed for the longest time to the highest temperature. In general, no diffusion or migration of elements was observed, apart for aluminum (detected with the use of SIMS). It was striking that Cadmium diffusion, as was observed by Ramanathan et al. after heating the solar cells at $400^{\circ} \mathrm{C}$, was not observed [2]. SIMS measurement demonstrated a possible migration of aluminum from the front contact layer to the CIGSSe absorber layer (Figure 9). Chirila et al. [8] also observed Al diffusion; indeed they used an $\mathrm{Al}$ flexible substrate and a migration of $\mathrm{Al}$ from this flexible layer to CIGSSe layer has been detected with SEM-EDX and SIMS. Even if a possible $\mathrm{Al}$ diffusion has been observed, the reduction of $\mathrm{Al}$ from the AZO layer has a small effect on the solar cell performance.

\section{Discussion on Barrier Formation}

$I V$ and EQE measurements indicate almost no variations in terms of $J_{\mathrm{SC}}$ and $V_{\mathrm{OC}}$. The filters experiment, plotted in Figure 7, can indicate that the $I V$ barrier, which produces difficulties related to the electrons extraction, is likely present in the $\mathrm{p}-\mathrm{n}$ junction region. By combining the filter experiments with the results of SIMS and cross-sectional SEM and with the information from the literature [8] one possible explanation of the barrier can be derived. Chirila et al. [8] observed a diffusion of $\mathrm{Al}$ from the substrate to the CIGSSe absorber layer and described that $\mathrm{Al}$ could act as a trap point in the absorber.

In our heating experiment an opposite diffusion of $\mathrm{Al}$ has been detected: the Al diffusion observed with SIMS was from the front contact to the CIGSSe absorber layer. The aluminum present in the absorber layer could produce traps point which provoked recombination of electrons-holes pairs. These effects could affect the extraction of electrons from the solar cells and by doing this reduction of the performance of them is affected. The Al diffusion could therefore be the cause for the $I V$ barrier, while the diffusion from the front contact to the CIGSSe absorber layer could have a second effect: it could decrease the conductivity of the front contact layer, and by doing so it influences the series resistance of the solar cells [8].

\section{Conclusions and Outlook}

The CIGSSe solar cells exposed for 30 seconds did not show any barrier formation in the $I V$ curve (Figure 5). Moreover, only in the case of 30 seconds no shunts on the mechanical scribe lines (Figure 8) were observed. Regarding the efficiency, the reduction after an exposure of $300^{\circ} \mathrm{C}$ for 30 seconds was limited to $2-3 \%$ (Figure 3). On the other hand, in the cases of 300 and 600 seconds the efficiency dropped by $29 \%$ and $48 \%$, respectively. Furthermore, for the last two cases lock-in thermography indicated a formation of shunts on the P3 scribed lines. The electrical properties, analyzed with EQE and $I V$ measurements, showed almost no changes in $J_{\mathrm{SC}}$ and $V_{\mathrm{OC}}$. Concerning the shunt resistance, the reduction was in the range of $5 \%$ for all the three time periods. The series resistances could not be easily calculated, since the slopes of the curves were affected by the barrier, which led to bending of the $I V$ curve. The $I V$ slope increase around open circuit conditions was negligible for the 30 seconds; meanwhile for the 300 and 600 seconds the increase was almost exponential and it was the main cause for the high drops in terms of fill factor (50\%). The results demonstrate that CIGSSe solar cells 

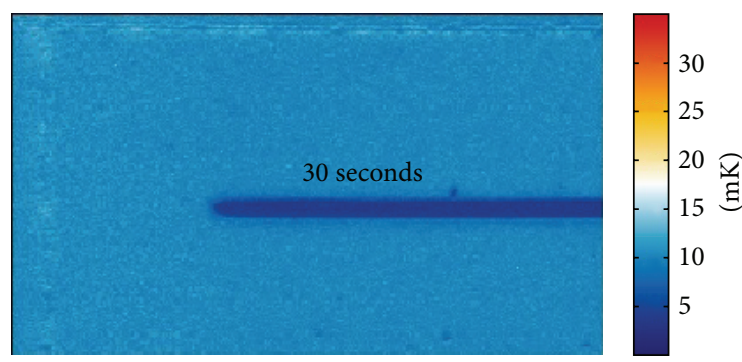

(a)

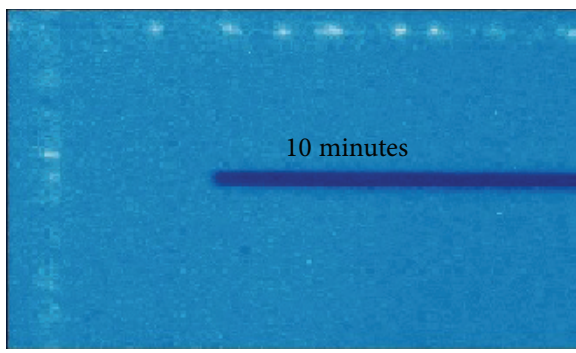

(c)

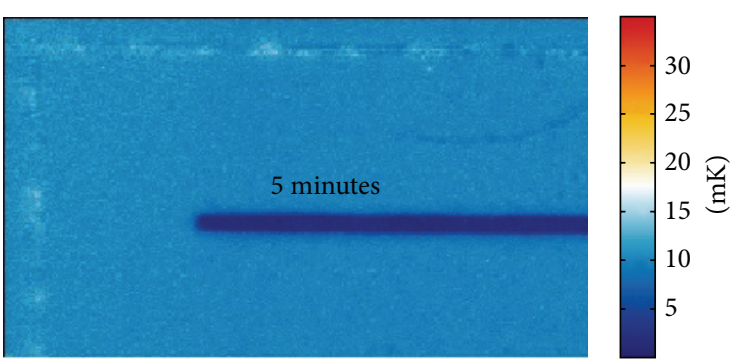

(b)

FIgURE 8: LIT images of sample heated for 30 seconds (a), 300 seconds (b), and 600 seconds (c) after being exposed to $300^{\circ} \mathrm{C}$.

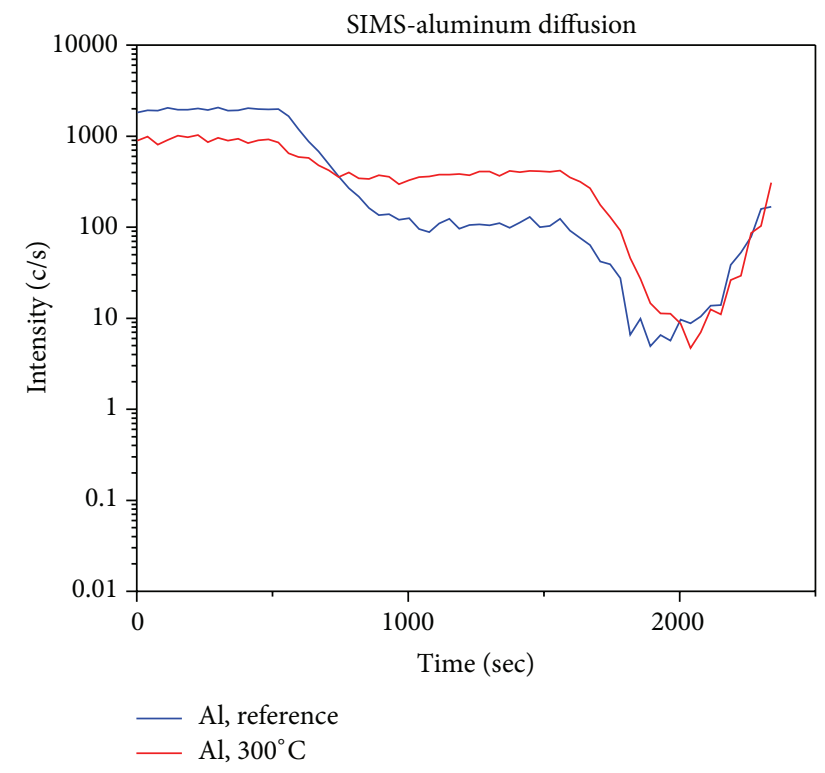

FIGURE 9: SIMS measurements showing Al diffusion from front contact to CIGSSe absorber layer. In blue the reference sample and in red the sample at $300^{\circ} \mathrm{C}$ for 600 seconds.

were able to withstand until $225^{\circ} \mathrm{C}$ in air atmosphere even for 600 seconds. At higher temperatures $I V$ barrier which reduced the extraction of carriers and reduced the solar cell performance was observed. Future experiments should focus on noncumulative heat treatment as well. Moreover, it would be interesting to heat the solar cells under vacuum or inert conditions, in order to understand the influence of air on the degradation of the solar cells.

\section{Competing Interests}

The authors declare that they have no competing interests.

\section{Acknowledgments}

The authors would like to thank Klaas Bakker and Henk Steijvers (TNO) for the fruitful discussions. Also, many thanks goes to Bertil Okkerse (Philips Innovation Services) and Denis Mangin (Université de Lorraine) for their assistance with the measurements or analysis.

\section{References}

[1] M. A. Green, K. Emery, Y. Hishikawa, W. Warta, and E. D. Dunlop, "Solar cell efficiency tables (version 47)," Progress in Photovoltaics: Research and Applications, vol. 24, no. 1, pp. 3-11, 2016.

[2] K. Ramanathan, M. A. Contreras, J. R. Tuttle et al., "Effect of heat treatments and window layer processing on the characteristics of CuInGaSe $e_{2}$ thin film solar cells," in Proceedings of the 25th IEEE Photovoltaic Specialists Conference, pp. 837-840, May 1996.

[3] S. Kijima and T. Nakada, "High-temperature degradation mechanism of $\mathrm{Cu}(\mathrm{In}, \mathrm{Ga}) \mathrm{Se}_{2}$-based thin film solar cells," Applied Physics Express, vol. 1, no. 7, Article ID 075002, 2008.

[4] D. S. Chen, J. Yang, F. Xu et al., "Effect of rapid thermal annealing on the compositional ratio and interface of $\mathrm{Cu}(\mathrm{In}, \mathrm{Ga}) \mathrm{Se} 2$ solar cells by XPS," Applied Surface Science, vol. 264, pp. 459463, 2013.

[5] X. Wang, S. S. Li, W. K. Kim et al., "Investigation of rapid thermal annealing on $\mathrm{Cu}(\mathrm{In}, \mathrm{Ga}) \mathrm{Se}_{2}$ films and solar cells," Solar Energy Materials and Solar Cells, vol. 90, no. 17, pp. 2855-2866, 2006. 
[6] J.-H. Wi, T. G. Kim, J. W. Kim et al., "Photovoltaic performance and interface behaviors of $\mathrm{Cu}(\mathrm{In}, \mathrm{Ga}) \mathrm{Se}_{2}$ solar cells with a sputtered-Zn $(\mathrm{O}, \mathrm{S})$ buffer layer by high-temperature annealing," ACS Applied Materials and Interfaces, vol. 7, no. 31, pp. 1742517432, 2015.

[7] F. Liu, Y. Sun, Q. He, and Z. Zhou, "Rapid thermal annealing on $\mathrm{dS} / \mathrm{Cu}(\mathrm{In}, \mathrm{Ga}) \mathrm{Se} 2$-based solar cells," in Proceedings of the International Conference on Materials for Renewable Energy and Environment (ICMREE '13), pp. 143-146, Chengdu, China, August 2013.

[8] A. Chirila, S. Buecheler, F. Pianezzi et al., "Highly efficient $\mathrm{Cu}(\mathrm{In}, \mathrm{Ga}) \mathrm{Se}_{2}$ solar cells grown on flexible polymer films," Nature Materials, vol. 10, no. 10, pp. 857-861, 2011. 

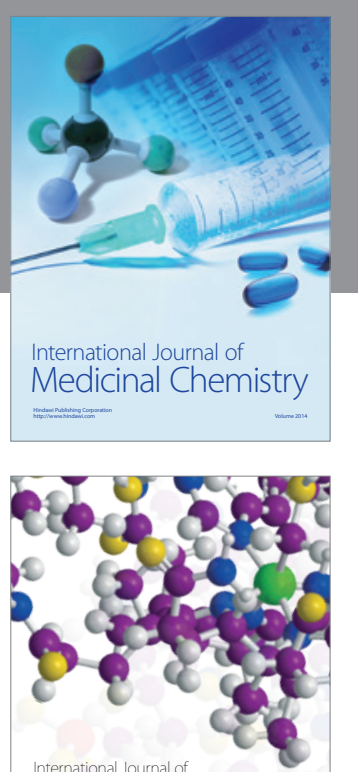

Carbohydrate Chemistry

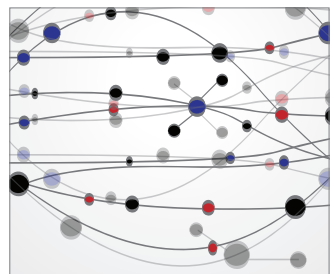

The Scientific World Journal
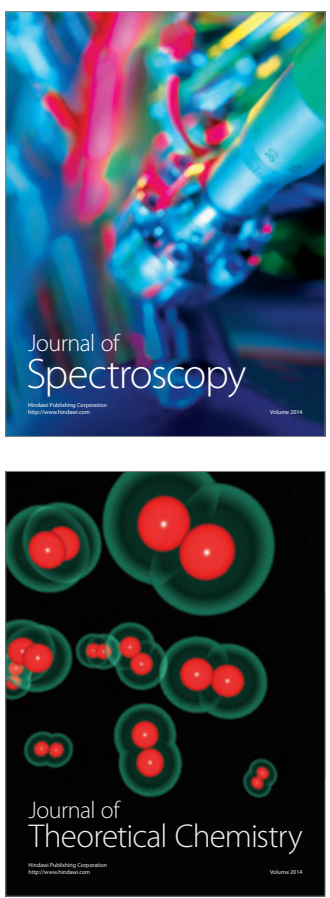
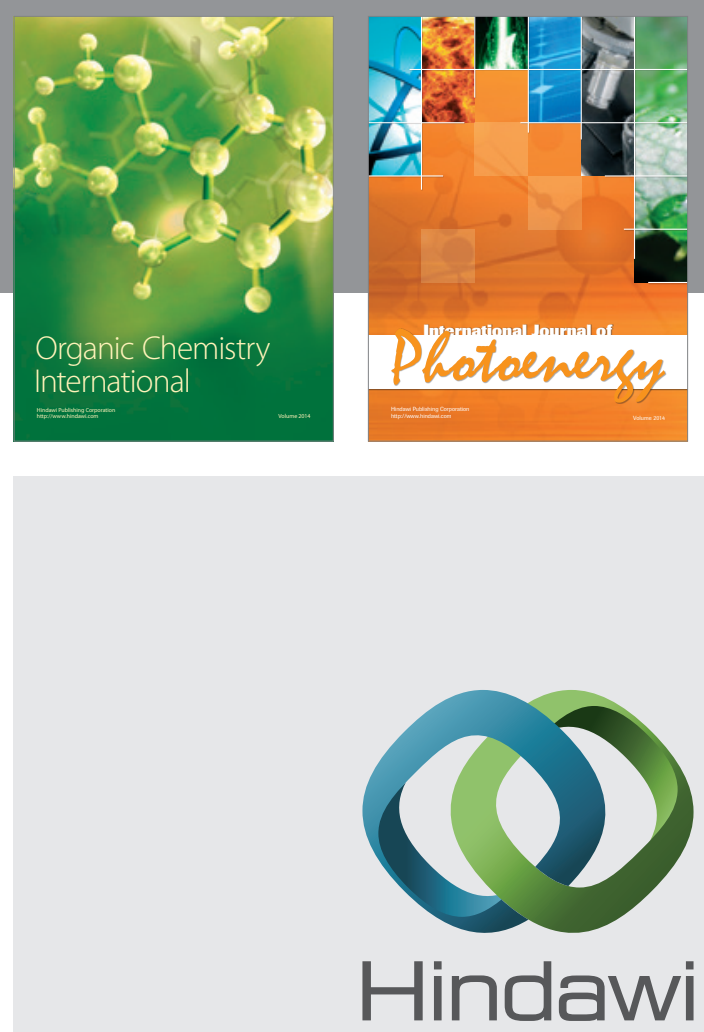

Submit your manuscripts at

http://www.hindawi.com

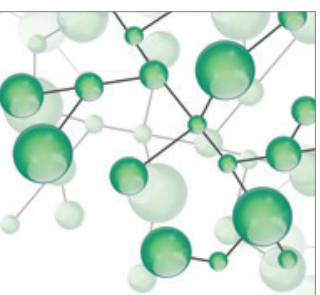

International Journal of

Inorganic Chemistry

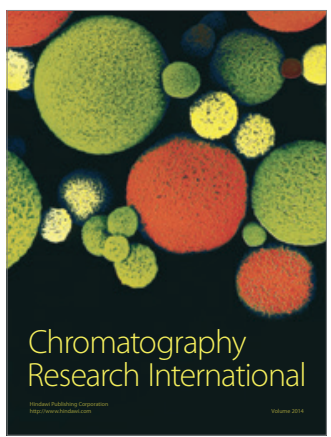

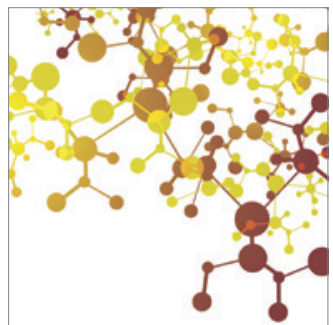

Applied Chemistry
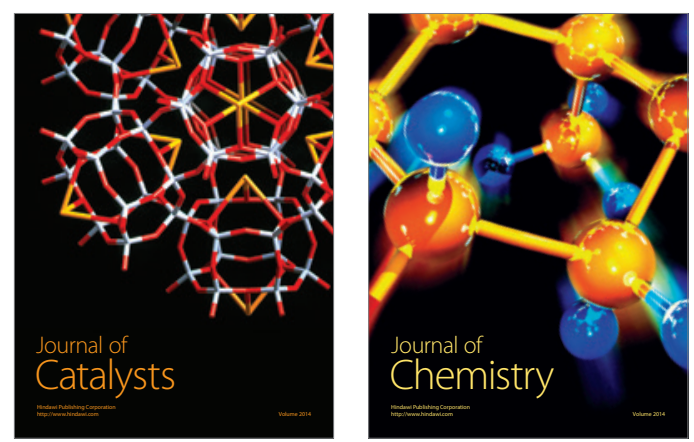
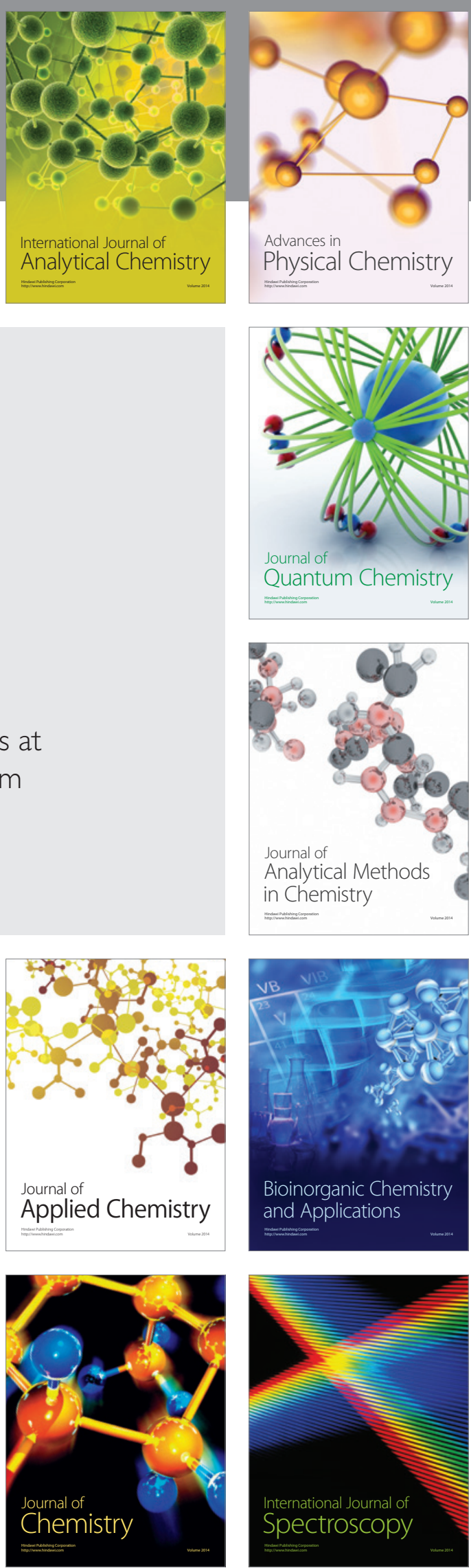